\title{
Freudiaans-antropologiese vooronderstellings in die neo-Marxistiese skool- en maatskappykritiek
}

\author{
Daniella Coetzee \\ Dept. Wysgerige Pedagogiek \\ Universiteit van die Oranje-Vrystaat \\ BLOEMFONTEIN
}

\begin{abstract}
Dissatisfaction with education in South Africa has given rise to diverse and politically radical school criticism. The educational views of anti-establishment schools of thought (eg. Marxism-Leninism, neo-Marxism, Contraculture, New Age Movement and the ideas of Paolo Freire) are extremely relevant to the current situation of education in South Africa. This article therefore emphasizes specific anthropological suppositions underlying neoMarxist culture and critique of society. Although Marxist influence on Emancipatory Education is acknowledged, emphasis is placed on Freudian roots of the neo-Marxist view on education. The influence of the Freudian personality theory on a selection of relevant themes, such as oppression in a capitalist society; politization of education; religion and repression of instincts is underlined. In conclusion it is shown that a school of thought that is based on deterministic suppositions abounds with inherent difficulties and can be regarded as educationally unsound.
\end{abstract}

\section{Oriëntering}

Vanweë sy kultuur- en maatskappykritiese karakter bly die opvoedkunde van anti-establishment-denkers (waaronder die Marxisme-Leninisme, neo-Marxisme, kontrakultuur, New Age Beweging, die denke van Paolo Freire ens.) steeds aktueel vir die Suid-Afrikaanse situasie waar veranderinge op alle fronte aan die gang is. Ontevredenheid met die opvoedkundige status quo in die RSA het aanleiding gegee tot uiteenlopende, soms polities-radikaal georiënteerde skoolkritiek. Die propagering van People's Education (wat aansluit by genoemde kultuur- en maatskappykritiese strominge) het die aandag opnuut gevestig op die antropologiese aannames waarop sodanige denkrigtings gegrond is. Hier kan veral verwys word na die sogenaamde Emansipatoriese Pedagogiek wat gedurende die sestigerjare sy beslag gekry het en sedertdien ontwikkel het tot een van die belangrikste eietydse maatskappykritiese benaderings in die opvoedkunde 
In die lig van die belangrikheid wat die Emansipatoriese Pedagogiek vir die huidige skool- en kultuurkritiek inhou, sal in hierdie artikel gepoog word om genoemde denkrigting te beoordeel teen die agtergrond van die onderliggende antropologiese vooronderstellings. Hoewel die neo-Marxistiese opvoedkunde grootliks gegrond is op Marxistiese en eksistensialistiese aannames, kan die Freudiaanse wortels daarvan nie as onbeduidend beskou word nie. Die mensbeeld wat hierdie opvoedkundige gedagterigting ten grondslag lê, blyk by nadere ondersoek gegrond te wees op ' $n$ Freudiaanse revisionisme. Die vraag ontstaan ook of hierdie kultuur- en maatskappykritiese denkrigting beantwoord aan die eise vir antropologiese en pedagogiese 'toelaatbaarheid'.

\section{Oorsprong van die Emansipatoriese Pedagogiek}

Dit was veral ' $\mathrm{n}$ groep academici (w.o. Herbert Marcuse, Max Horkheimer, Theodor Adorno, Erich Fromm en Jürgen Habermas), bekend as die Frankfurter Schule wat 'n groot bydrae gelewer het tot die uitbouing van die sogenaamde Kritische Theorie as anti-outoritêre, maatskappy-kritiese lewensfilosofie (Schoeman, 1980:2). Onder invloed van hierdie denkskool het 'n groep opvoedkundiges (w.o. Klaus Mollenhauer, Hartmut von Hentig, Hans-Jochen Gamm, Gerhard Bott en andere) na vore getree (Henning, 1988:18), wat as eksponente van die sogenaamde Emansipatoriese Pedagogiek sterk aangeknoop het by die psigo-analitiese tradisie van die twintigerjare (vgl. Hengst, 1973:201-202). Die belangstelling wat lede van die Kritiese Teorie in die gedagtes van Freud getoon het, kan reeds so ver teruggevoer word as die pogings van Erich Fromm (gedurende die vroeë dertigerjare) om 'n sintese tussen historiese materialisme en dieptepsigologie te bewerkstellig. Hierin het hy ook gebruik gemaak van Wilhelm Reich se interpretasie van Freud in die lig van die sosiale radikalisme (Schoeman, 1979:41-42).

Weens sy noue verbintenis met Fromm en Reich is dit vanselfsprekend dat ook Herbert Marcuse hom sou wend tot die dieptesielkunde. Hy het hom ten doel gestel om die sogenaamde hidden trends (dit wil sê motiewe en tendense wat deur Freud sélf nie ingesien is nie) in Freud se kultuurkritiek bloot te lê (Marcuse, 1974:11-20). Hierdie verborge motiewe sou vervolgens dien as grondslag vir die ideologiese struktuur van sy kritiese teorie (Schoeman, 1979:42). Vir Marcuse (1974:35) is die verborge motiewe van die psigo-analise ten eerste geleë in die ontmaskering van ' $n$ onderdrukkende realiteitsbeginsel wat die selfvervreemding van arbeid en arbeider handhaaf. In die lig hiervan meen Marcuse (1974:5) dat Freud beweeg het in die rigting van ' $n$ versoening van die realiteitsbeginsel met die lusbeginsel. Die psigo-analitiese anamnese van ' $n$ verlore paradys waarin net die lusbeginsel sou geheers het, kan hiervolgens dien as 'wegwyser' na 'n nuwe realiteit, 'n sogenaamde "non-repressive civilization" (Marcuse, 1974:5). In sy soeke na kritiese en selfs rewolusionêre elemente (vgl. Rohrmoser, 1976:70-76) in die vroeë psigo-analitiese denke het Marcuse hom hoofsaaklik toegespits op 
Freud se meta-psigologiese teorieë. Hieronder is veral die instinkte-teorie van Freud en sy opvattings ten opsigte van die sogenaamde argaïese erfenis van die mens van betekenis (vgl. Marcuse, 1974:6; 1970:6; asook Schoeman, 1979:43; Robinson, 1970:149; Zuidema, 1970:8-9).

\section{Aansluiting by Freud se kultuurkritiek}

Soos in die geval van Freud ervaar Marcuse 'n Unbehagen in die kapitalistiese welvaartmaatskappy (Zuidema, 1970:9). Hy stem ook saam met Freud dat kultuurhandhawing prinsipieel gepaard gaan met onvryheid, dit wil sê met onderdrukking van die ware aard van die mens (Schoeman, 1979:45): "Within the framework of civilization which has become historical reality, freedom is possible only on the basis of unfreedom, that is, on the basis of instinctual suppression" (Marcuse, 1970:5; vgl. ook Freud, 1930:105). Ooreenkomstig hierdie siening van Freud is die geskiedenis van kultuur vir Marcuse ook sinoniem met "die Geschichte sukzessiver Unterdrückung und Verdrängung an sich möglicher Versöhnung" (Rohrmoser, 1976:75). Die mens verkeer dus in 'n tragiese toestand van onderdrukking. Hy word deur die realiteitsprinsipe gedwing om kultuur te skep wat tegelykertyd sy ondergang beteken (Schoeman, 1979:47). Omdat Freud oënskynlik vasgevang is in 'n biologistiese determinisme is dit nie verbasend dat sy kultuurkritiek deur 'n uiterse pessimisme gekenmerk sal word nie. Hoewel Marcuse en ander neo-Marxistiese aanhangers van Freud strewe na volledige ontplooiing van individuele vryheid as hoogste lewensideaal in 'n nie-repressiewe maatskaplike ordening (Henning, 1988:22), is hulle met die oog op die moontlike verwesenliking van dié ideaal ook nie optimisties ingestel nie. Hulle weier egter om hulle hoop vir die toekoms in te stel op iets anders as hulle eie humanistiese ideale (Henning, 1988:20). Volgens Schoeman (1979:47; 49) is Marcuse egter nie dieselfde sterk fatalistiese mening as Freud toegedaan nie. Sy kritiese teorie is immers gemoeid met die ontwerp van 'n nuwe onderdrukkingsvrye samelewing. Ten einde hierdie ideaal teen oorwoekering van die establishment te verskans dring hy dan ook aan op die "Great Refusal" as 'n "protest against unnecessary repression, the struggle for the ultimate form of freedom - to live without anxiety" (Marcuse, 1970:150), 'n houding wat volgens Schoeman (1980:7) "vanweë sy uitsiglose pessimisme en negatiewe karakter nêrens tereg kan kom nie".

Dog ten spyte van hierdie kultuur-pessimistiese ingesteldheid, is dit vir neoMarxistiese eksponente van die opvoedkunde 'n opgawe om deur middel van hulle maatskappykritiek 'n "nuwe koers" aan te dui wat sal lei tot die aktualisering van 'n nuwe, nie-repressiewe kultuur (Schoeman, 1980:8). 


\section{Opvoeding tot maatskappykritiek}

Die hooftema van die neo-Marxisme wat ontwikkel het uit die Freudiaanse kultuurbeskouing, naamlik maatskappykritiek, is vervolgens ook deur eksponente van die Emansipatoriese Pedagogiek aangegryp. In pas met die neo-Marxistiese kritiese ingesteldheid is dit dan ook volgens Klaus Mollenhauer (Brezinka, 1972: 121) die doel van die pedagogiek om "in der heranwachsenden Generation das Potential gesellschaftlicher Veränderung hervorzubringen". Vir die neo-Marxis beteken die woord Emanzipiert volgens Brezinka (1972:122), vryheid van die bindinge van geloof, norme en alle instansies wat gesien kan word as 'n verpersoonliking van die gehate welvaartmaatskappy. In pas hiermee is opvoedingsdoelstellings radikaal maatskappykrities van aard en is talle uitsprake in die pedagogiese geskrifte van neo-Marxiste pleitredes vir opvoeding tot 'n permanente maatskappykritiese gees, politieke strydbewustheid en strydvaardigheid (Henning, 1988:132). Ook ten opsigte van die verpolitisering van opvoeding en onderwys is die Freudiaanse invloed dus duidelik aanwysbaar. Fromm en sy medewerkers het gemeen dat Freud se pan-seksualisme, sy psigiese determinisme (gefokus op die vroeë kinderjare), sy konsep van die doodsinstink, sowel as sy "explicit denial of the meaningfulness of social and political reform" (Robinson, 1970:148), die belange van politieke hervorming sou bevorder.

Die tegnies-wetenskaplike kultuur wat op die wetenskap en tegniek gegrond is word ook deur aanhangers van die neo-Marxisme beskou as 'n determinerende mag wat die mens van sy outentieke menswees vervreem (Schoeman, 1980:14). Van die sogenaamde "technische Produktivität" sê Von Hentig (1974:28): "Sie hat freilich auch die Lebensformen selbst drastisch verändert, sie in einem Maße "entfremdet". Dit is dus die vooruitgang van die huidige tegnologie as 'n manifestering van die Herrschaftsprinzipe in die repressiewe maatskappy wat hier afgewys word. Die neo-Marxistiese kritiek is volgens Marcuse (1980:248) nie teen die wetenskap sélf gerig nie, maar teen "de gangbare technologische rationaliteit" wat bydra tot die eendimensionaliteit van die hedendaagse samelewing deur die mens aan produksie-apparate te onderwerp (Marcuse, 1980:52). In plaas van die gevestigde tegnologie, wat 'n instrument van destruktiewe politiek geword het, pleit Marcuse (1980:244) dus vir 'n "technologische omvorming" waaruit 'n "nieuwe technologie" sou ontwikkel. Daar moet gevolglik nie weggedoen word met die "technische basis" van die samelewing nie, want dit "blijft dan ook de basis van alle vormen van menselijke vrijheid" (my kursivering DC) (Marcuse, 1980:248). Hierdie stukkie suiwer rasionalisme is die uitkoms van die humanistiese wetenskapsideaal in die denke van Marcuse: hy aanvaar dat sy vrymaking van die repressiewe kultuur bewerkstellig sal word deur die wetenskap - met ander woorde sy verabsoluteerde redelike vermoëns. Teen die agtergrond van sy indeterministiese ingesteldheid wat tot uiting kom in die strewe na 
absolute, ongebonde vryheid, kan sy denke waarskynlik as indeterministiese rasionalisme getipeer word.

Die Freudiaanse afwysing van die onderdrukkende maatskappy as die oorsaak van die mens se ellende word deur neo-Marxiste oënskynlik indeterministies vertolk. Die opvatting dat die mens se sosiale situasie egter bepaal word deur sy argaiese erfenis en eersgenoemde verantwoordelik is vir die dehumanisering van die kleinburgerlike mens (Schoeman, s.a.:16), dui egter onteenseglik op 'n invoer van deterministiese elemente in die mensbeskouing van eksponente van die neoMarxisme. Hoewel die maatskappykritiek van die neo-Marxistiese opvoedkunde dus in die tradisie staan van die spanning tussen deterninisme en indeterminisme en gevolglik 'n eensydige en skeefgetrekte benadering tot die opvoedingswerklikheid meebring, hou hierdie kultuurkritiek vir die reformatoriese opvoedkundige tóg waarde in. Volgens Schoeman (s.a.:18) hou dít verband met die "oproep tot die aflegging van kritieklose aanvaarding van die status quo" (my kursivering).

\section{5. 'n Onderdrukkingsvrye onderwyspraktyk}

Die neo-Marxistiese ideaal van 'n repressievrye opvoedingspraktyk hou sterk verband met die maatskappykritiese ingesteldheid wat hierbo bespreek is. Die wyse waarop die neo-Marxisme tot gesagsondermyning en opvoeding tot ongehoorsaamheid wil kom, is deur die aard van verantwoorde tuguitoefening te ontken (Strauss, 1982:3). Onder beslag van die humanistiese persoonlikheidsideaal word 'n sogenaamde 'Ek-pedagogie' toegepas, waardeur die kind in staat gestel moet word on sy persoonlike behoeftes te bevredig (Henning, 1988:3536). Die rol van die gesagsfiguur is dus vervang met "dié van 'behoeftebevrediger'". Vryheid word dus gesien as outonome selfbepaling: "Die wáre mens is die vrye, gelukkige mens - vry van uiterlike bindinge en vry tot hevrediging van die eie libido" (my kursivering - DC) (Esterhuyse, 1971:15; vgl. ook Van Wyk, 1979:130). Dit wil dus voorkom asof die neo-Marxistiese siening aangaande die onderdrukkende maatskappy gewortel is in die Freudiaanse siening van verdringing (Rauch, et al., 1973:26-27). Die volgende stelling van Freud is hier van toepassing: "Just as a satisfaction of instinct spells happiness for us, so severe suffering is caused us if the external world lets us starve, if it refuses to sate our needs" (Freud, 1930:78-79). Ook die neo-Marxistiese opvoedkundige Hans-Jochen Gamm het Freud se teorie oor verdringing sy eie gemaak. Hy meen dat alle opvoeders grondig moet kemnis neem van Freud se instinkteleer omdat spanning en konflikte wat gepaardgaan met onderdrukking van die libido ' $n$ belangrike rol speel gedurende puberteit (Gramm, 1974:14; vgl. ook pp.130-131).

Gevolglik word op eg indeterministiese wyse totale vryheid bepleit sodat die kind sy drifte op 'n onbelemmerde wyse kan bevredig. Word hierdie vryheid egter gerealiseer, is die mens terselfdertyd gedetermineer deur sy instinkte en (teen- 
Freudiaans-antropologiese vooronderstellings

strydig hiermee) ook ten volle vry om hierdie drifte te bevredig. Hier is dus 'n duidelike spanning tussen determinisme en indeterminisme in die neo-Marxistiese gedagtegang aan te wys.

Ook godsdiens word as 'vervreemdend' en 'dehumaniserend' beskou. Gamm (1974:181) meen dat 'n "entrümpelte Anthropologie" verantwoordelik is daarvoor dat die Christendom die 'wanklanke' in die samelewing versluier. As sodanig sluit hy hom aan by Freud wat godsdiens beskou as "the obsessional neuroses of mankind" (Freud, 1927:43) wat in die algemeen uitloop op "depressing the value of life and distorting the picture of the real world in a delusional manner" (Freud, 1930:84; vgl. ook p. 87). Gamm meen ook dat die uitsprake van Freud (waardeur die mens finaal van enige religieuse gebondenheid bevry is), nie deur die antropologie van die "bürgerlichen Bewußtseins" (dit wil sê die Christendom), aanvaar en verwerk is nie, maar eerder verdring is (Gamm, 1974:181). Die Christelike godsdiens het volgens Gamm dus grootliks daarin geslaag om die realiteit (wat Freud aangetoon het) te verdoesel. Die opgawe van die opvoeding is vir Gamm duidelik: deur opvoeding moet alle valshede wat daarop gemik is om die realiteite van die werklikheid te laat vervaag, ontmasker word (Gamm, 1974:181). Hierdie deterministiese aanslag van Gamm vind sterk aanklank by die volgende uitspraak van Freud (1927:35): "I shall assert the view that civilization runs a greater risk if we maintain our present attitude to religion than if we give it up". In pas hiermee bepleit Gamm 'n nuwe benadering ten opsigte van 'metafisiese idees'. Hy wil "die sogenaamde antieke, metafisiese, godsdienstige bevangenhede en die Christelike lewens- en wêreldbeskouing vervang met ' $n$ werklikheid met sogenaamde konkrete gestalte" (Henning, 1988:140-141).

Ook Von Hentig se siening dat godsdiens alleenlik bestaansreg het binne die konteks van "mythischen Erklärungen, symbolischen Darstellungsformen, rituellen Handlunge" (Von Hentig, 1974:101) kan in dieselfde kategorie geplaas word as Freud se evolusionistiese verklaring oor die ontstaan van godsdiens uit die Oedipus-kompleks (vgl. Totem and Taboo (1913) en Moses and Monotheism (1939)). Von Hentig se rasionalistiese aandrang op ' $n$ vervanging van godsdiens by die kind met "strengeren Formen der Rationalität" (1974:102) sluit verder ook aan by Freud se siening in The Future of an Illusion (1927:54-56), naamlik dat die wetenskap die religie moet vervang. Die noodwendige konsekwensie van hierdie redeverheerliking van eksponente van die Emansipatoriese Pedagogiek is 'n miskenning van al die ander uitgange waarin die menslike persoonlikheid tot uitdrukking kom. Rede en geloof word gesien as teenpole en die mens vind sy hoogste kwalifikasie in sy logiese funksie, terwyl alle ander uitgange uit die psigiese afgelei word. Wanneer wetenskap en geloof egter hulle regmatige plek ten opsigte van die uitgange van die totale mens inneem, dan kan die uitwerking van die godsdiens nie meer gesien word as onderdrukkend en verslawend nie. Om 
godsdiens egter te reduseer tot 'n vader-identifikasie of skuldkompleks kan gesien word as 'n miskenning van die ware religieuse aard van die mens.

\section{Onderdrukking deur die prestasiebeginsel}

Die neo-Marxistiese aandrang op die vervanging van die prestasie- of realiteitsbeginsel met die lusprinsipe hou verder ook verband met Freud se libido-teorie. Kultuur word volgens Freud moontlik gemaak deur die handhawing van die realiteitsbeginsel. Die taak van hierdie beginsel is om die lusprinsipe te onderdruk en as sodanig verteenwoordig dit 'n sisteem wat opgebou is uit aanpassing, onderdrukking, afwyking en sublimasie van instinkte wat die gemeenskap op die mens moet afdwing ten einde hom van 'n drif-gedrewe wese in 'n sosiaal bruikbare lid van die samelewing te verander (vgl. Marcuse, 1970:34; asook Freud, 1920:1011 ; 24-64; 1923:45-47; 1930:76-97; Nicolas, 1972:155; Zuidema, 1979:45-46). In hierdie $\sin$ is die realiteitsbeginsel identies met die prestasieheginsel want "it is through the repressive reality principle that instinctual energy first becomes released for unpleasurable labor, for labor that has learned to renounce, to deny instinctual wishes and that can become and remain socially productive only in this way" (Marcuse, 1970:34). Volgens Marcuse (1970:5) is kultuur dus sublimasie of onderdrukking: "postponed, methodically controlled satisfaction which presupposes unhappiness. The 'struggle for existence', 'scarcity' and cooperation all compel renunciation and repression in the interest of security, order, and living together".

Die prestasiebeginsel hou vervolgens vir neo-Marxistiese opvoedkundiges verband met die tradisionele evalueringstelsel in die outoritêre Westerse skool en die repressiewe uitwerking wat dit op die kind het. Gamm (in Henning, 1988:50) beskou die stelsel van evaluering in bogenoemde skole as 'n "verwerplike argaïese oorblyfsel van uitgediende deterministiese, godsdienstige en ander rituele van magsuitoefening". Ook Von Hentig (1974:141-145) bevraagteken die sinvolheid van evaluering in die opvoedingsopset en koppel dit aan die "onderdrukkende prestasiebeginsel" (1974:142). Indien alle prestasie in die opvoedingsopset in terme van meetbaarheid uitgedruk word, sou die opvoeding nie alleen dehumaniserend wees nie, maar ook sinloos (Von Hentig, 1974:145).

\section{Vryheid tot drifbevrediging}

Dit is veral op die gebied van seksualiteit dat eksponente van die neo-Marxisme en Emansipatoriese Pedagogiek aanklank gevind het by die teorieë van Freud. Laasgenoemde se reduksionistiese siening van die mens as gedetermineer deur die lusbeginsel is deur opvoedkundiges aangegryp en op verbeeldingryke wyse uitgebou tot 'n oortuiging dat die wese van die mens se geluk, asook sy ware vryheid in die bevrediging van die Eros-instinkte gevind kan word. 'n Strewe na 
(seksuele) genot is dus 'n strewe na vryheid (Zuidema, 1970:10; Robinson, 1970:207; 215; Henning, 1988:108-109; Marcuse, 1974:xv; Klapwijk e.a., 1974: 119; Anzinger, 1973:326; Van Dijk, 1974:24). Hieruit volg 'n kritiese ingesteldheid teenoor die onderdrukking van seksualiteit in die algemeen. Marcuse beskou "bodily repression" en in besonder seksuele onderdrukking as een van die mees belangrike kenmerke van die uitbuitende sosiale orde (Robinson, 1970 188). Volgens hom is Eros deur die onderdrukkende maatskappy gedeseksualiseer, gereduseer tot blote (genitale) seksualiteit sodat die mens 'n potensiële arbeidsinstrument is (Marcuse, 1970:34-35). Uit hierdie toestand van vervreemding moet die mens se seksualiteit dus verlos word. Dit moet bevry word van die beperkings van 'n onderdrukkende prestasiebeginsel en weer Eros word, dit wil sê 'n 'liefdes-energie' wat die ganse lewe van die mens beheers (Marcuse, 1970:3940; asook Schoeman, 1979:72).

Ook vir Wilhelm Reich was die verband tussen seksuele onderdrukking en die kapitalistiese outoritêre maatskappy duidelik: die kind wat in sy natuurlike seksualiteit onderdruk word, se karakterontwikkeling word geskend (Robinson, 1970:50). Die enigste hoop op bevryding is dus 'n politieke en seksuele rewolusie (Anzinger, 1973:326). Die neo-Marxistiese Sexualpedagogik verteenwoordig vervolgens 'n onmiskenbare teruggreep op Reich se denke en veral ten opsigte van hulle strewe na individuele geluk deur genotservaringe en repressielose, vitale drifbevrediging (vgl. Anzinger, 1973:326; asook Henning, 1988:108). Hoewel Freud seksualiteit op die voorgrond geplaas het, het hy met 'n strewe na genot nie uitsluitlik genitale seksualiteit bedoel nie, maar eerder algemene seksualiteit of hedonisme. Dit wil egter voorkom asof eksponente van dié anti-outoritêre opvoedingsbeweging uitgegaan het van 'n onjuiste vertolking van Freud (en veral Marcuse) en benewens 'n hedonistiese ingesteldheid ook vrye (genitale) seksualiteit en promiskuiteit gepropageer het.

Bott sluit aan by Freud se uitspraak van die mens as polimorf-pervers (1972:23). Hoewel die sogenaamde 'Lus-Ek-beginsel' volgens Bott in hoofsaak dien om vrye (genitale) seksualiteit te regverdig, word dit egter ook afgestem op die ontplooiing van die lus tot denke, spreke, waarneming, leer, ken, werk ens. (Henning, 1988:111). In hierdie verband kan ook verwys word na Three Contributions to the Theory of Sex (1905:602) waarin Freud die verband tussen intellektuele werk en seksuele stimulasie beklemtoon. Só word die ganse neo-Marxistiese opvoeding hedonisties in diens gestel van die erotiese. Die lusprinsipe word verhef tot alles-oorkoepelende beginsel, sodat ons hier te doen het met 'n redusering van die ganse opvoedingswerklikheid tot blote sinnelike gevoel. Hoewel die humanistiese ideaal van 'n (outonome) vrye menslike persoonlikheid in die Sexualpedagogik van die neo-Marxiste die botoon voer, word die mens steeds in navolging van Freud, beskou as die slaaf van sy drifte - 'n beskouing wat dui op 'n deterministiese aanname in hulle antropologie. En hierin word die inherente 
teenstelling tussen determinisme en indeterminisme wat kenmerkend is van die humanistiese denke, op 'n onmiskenbare wyse in die neo-Marxistiese Emansipatoriese Pedagogiek geillustreer. Transendent-krities gesien, is die siening van die mens as gedetermineer deur sy drifte, heeltemal onaanvaarbaar. Die instinkte staan onder leiding van die religieus gebonde hart van die mens en dit kan óf anastaties óf apostaties gerig word. Sodoende het seksualiteit by die mens, in onderskeid van die dier, nie allereers 'n biotiese kwalifiseringsfunksie nie, maar word dit gestempel deur die etiese uitgang van die mens. Dit beteken dat die mens se tipies menslike lewensfasette nie beheers word deur die lusbeginsel nie, maar volgens Strauss (1978:295) 'n "gerigtheid besit op die normatief-gestempelde toerekenbare beslissingsvryheid van die mens". Die opgawe vir die opvoeder is dus nie die 'vrymaking' van die kind van seksuele onderdrukking nie, maar wel die kanalisering van sy drifte op beheerste beskaafde wyse onder die beslag van norme (Schoeman, 1988:217-218).

\section{Waardebepaling}

Soos reeds genoem, is daar in voorgaande bespreking slegs dié momente van die neo-Marxistiese opvoedkunde uitgelig wat op een of ander wyse in verband staan met die persoonlikheidsbeskouing van die dieptesielkunde. Daar word dus geensins aanspraak gemaak op volledigheid ten opsigte van die Emansipatoriese Pedagogiek as opvoedkundige stroming nie.

Dit wil voorkom asof veral eksponente van die Frankfurter Schule, waaronder Marcuse en in 'n mindere mate ook Fromm, aanklank gevind het by die latere beskouings van Freud wat betref sy struktuurteorie van die menslike persoonlikheid. Die denkbeelde van Wilhelm Reich, Gamm, Bott en Von Hentig is waarskynlik gegrond op die vroeëre panseksualistiese fase van Freud se psigo-analise. Dit is egter deurgaans opvallend dat Freud se sentrale gedagtes van repressie en sy instinkleleer sonder uitsondering in die denkbeelde van elkeen van die eksponente, sowel as die onderskeie temas wat bestudeer is, 'n fundamentale rol speel. Dat die Emansipatoriese Pedagogiek sonder voorbehoud op die Freudiaanse reduksionistiese mensbeskouing gegrond is, lei dus geen twyfel nie.

Hoewel die Marxistiese wortels van die neo-Marxisme nie in hierdie studie gefigureer het nie, word die invloed daarvan wél erken. Rohrmoser verwys byvoorbeeld na Marcuse se teorie as "Freudmarxismus" (1976:67), terwyl Stark (Marcuse e.a., 1971:45) dit tipeer as "een socialisme op biologische grondslag ... Karl Marx verrijkt met Sigmund Freud". Ook Geisler et al. (1969:413) erken die invloed van Freud op Marcuse se neo-Marxisme: "Marcuses Begriff vom Sozialismus ist an Freud orientiert". 
Dit is verder duidelik dat ' $n$ immanent gewortelde antropologie bepaalde onoplosbare probleme, ook op die gebied van die opvoedkunde oplewer. Geldige (alhoewel eensydige en skeefgetrekte) kritiek vanuit neo-Marxistiese oord is egter op die Westerse welvaartmaatskappy en sy opvoedingsinstellings gelewer, wat 'n besondere taak van reformasie (in teenstelling met rewolusie) van die onderdrukkende strukture op grond van die gegewe kultuuropdrag voor die deur van die Christen-opvoedkundige en -opvoeder lê. Die oplossings wat neo-Marxiste vir bestaande probleme in die vooruitsig stel, kan egter, vanweë hulle verankerdheid in ' $n$ apostatiese grondmotief, nie van blywende waarde wees nie. Waar die wetsy en subjeksy van die werklikheid nie as korrelate beskou word nie, is dit onvermydelik dat die opvoedkundige denke in of ' $n$ eensydige determinisme, óf in 'n indeterminisme sal verval. In die geval van die neo-Marxistiese opvoedingsfilosofie blyk dit dat teorie gelykgestel word aan maatskappykritiek terwyl praktyk (opvoeding) beskou word as sosiale lewenswerklikheid. Die beoefening van opvoedkunde as wetenskap besit dus vir die neo-Marxistiese opvoedkundige slegs geldigheid in dié mate waarin dit diensbaar is aan die praktyk, dit wil sê solank dit gerig is op die emansipasie van die onderdrukte en gedehumaniseerde mens (Schoeman, 1980:16)

Soos in die geval van die Freudiaanse persoonlikheidsbeskouing, word die bestaan van universele en geldige norme deur die neo-Marxis ontken en word pedagogiese waarhede beskou as kontingent en situasiegebonde (vgl. Marcuse, 1980:167). Die neo-Marxistiese opvoedingfilosofie kan dus ten slotte getipeer word as ' $\mathrm{n}$ indeterministiese rasionalisme wat, ten diepste gegrond in die Freudiaanse mensbeskouing, ' $n$ manifestasie blyk te wees van die onoplosbare spanning wat tekenend is van die immanent gewortelde humanistiese grondmotief van natuur en vryheid.

\section{Verwysings}

ANZINGER, W. 1973. Sexualerziehung. (In Rauch, E. \& Anzinger, W., Wörterbuch Kritische Erziehung. Starnberg: Werner Raith Verlag. p. 325-326.)

BOTT, G. 1972. Opvoeding tot ongehoorzaamheid - Verslag uit de praktijk van de nietautoritäre opvoeding. Baarn : In der Toren, Anthos.

BREZINKA, W. 1972. Grundlagen, Ziele und Mittel "neulinken Pädagogik". Crificor, $11: 120-122$

ESTERHUYSE, W.P. 1971. Filosofie van die rewolusie. Johannesburg : Boekhandel De Jong.

FREUD, S. 1905. Three Contributions to the Theory of Sex. (In Brill, A.A., The Basic Writings of Sigmund Freud (vervolgens BWS). New York: The Modern Library. p. 600620.)

FREUD, S. 1913. Totem and Taboo. (In Brill, A.A., BWS. New York: The Modern Library. p. 79-145.)

FREUD, S. 1923. Introductory Lectures on Psycho-Analysis. London: George Allen \& Unwin Ltd. 
FREUD, S. 1920. Beyond the Pleasure Principle (In Strachey, J., Volume XVIII, The Standard Edition of the Complete Works of Sigmund Freud (vervolgens CPW). London: Hogarth Press. p. 10-64.)

FREUD, S. 1927. The Future of an Illusion. (In Strachey, J., Volume XXI, CPW. London Hogarth Press. p. 5-56.)

FREUD, S. 1930. Civilization and Its Discontents. (In Strachey, J., Volume XXI, CPW. London : Hogarth Press. p. 76-145.)

FREUD, S 1939. Moses and Monotheism. (In Strachey, J, Volume XXIII, CPW. London : Hogarth Press. p. 200-389.)

FROMM E. \& XIRAU, R. eds. 1968. The Nature of Man. Macmillan : New York.

GAMM, H.J. 1974. Einführung in das Studium der Erziehungswissenschaft. München : List Verlag.

GEISLER, U \& SEIDLER, H. 1969. Die romantische Kapitalismuskritik \& der utopische Sozialismusbegriff H. Marcuses. Deutsche Zeitschrift fuir Philosophie. 17:412-416.

HENGST, H. 1973. Kritische Theorie. (In Rauch, E. \& Anzinger, W., Wörterbuch Kritische Erziehung. Starnberg: Werner Raith Verlag. p. 200-204.)

HENNING, O.A. 1988. Die versetleer van vier linkse opvoedkundiges. Bloemfontein : N.G. Sendingpers.

KLAPWIJK, J. \& GRIFFIOEN, S. 1974. Kritiek op de Kritische Theorie V.U. Magazine, $8: 118-110$.

MARCUSE, H. 1970. Five Lectures. London : Compton Printing Ltd

MARCUSE, H. 1971. Geweld en vrijheid. Politieke opstellen. Amsterdam : De Bezige Bij.

MARCUSE, H. 1974. Eros and Civilization. A Philosophical Inquiry into Freud. Boston : Beacon Press.

MARCUSE, H. 1980. De een-dimensionale mens. Bassum : Uitgeverij Paul Brand

NICOLAS, A. 1972. Herbert Marcuse. Utrecht : Uitgeverij Het Spectrum N.V.

RAUCH, E. \& ANZINGER, W. 1973. Wörterbuch Kritische Erziehung. Starnberg : Werner Raith Verlag.

ROBINSON, P.A. 1970. The Sexual Radicals. London: Temple Smith

ROHRMOSER, G. 1976. Das Elend der Kritische Theorie. Freiburg : Verlag Rombach

SCHOEMAN, M.J. 1979. Waarheid en werklikheid in die Kritiese Teorie van Herbert Marcuse. Pretoria : J.L. van Schaik.

SCHOEMAN, P.G 1980. Emansipatoriese Pedagogiek. Pretoria : Butterworth \& Kie.

SCHOEMAN, P.G. 1988. Wysgerige Pedagogiek. Pretoria : Sacum Beperk

SCHOEMAN, P.G. s.j. Die mondige mens van die "emansipatoriese pedagogiek": spanning tussen die determinisme en die indeterminisme in neo-Marxistiese benaderings tot die pedagogiese antropologie. Ongepubliseerde artikel.

STRAUSS, D.F.M. 1978. Inleiding tot die kosmologie. Bloemfontein : Sacum.

STRAUSS, D.F.M. 1982. Die uitdaging van die neo-Marxisme op die gebied van die Wetenskap. Instituut vir Reformatoriese Studie, Nommer 14. Potchefstroom : Pro-Rege Pers

VAN DIJK, M.P. 1974. De uitdaging van het neo-Marxisme. Amsterdam : Buijten en Schipperheijn.

VAN WYK. J.H. 1979. Strominge in die opvoedingsteorie. Durban : Butterworth

VON HENTIG, H. 1974. Systemzwang und Selbstbestimmung - über die Bedingungen der Gesamtschule in der Industrie-gesellschaft. Stuttgart : Ernst Klett Verlag, 4. Auflage.

ZUIDEMA, S.U. 1970. De revolutionaire maatschappijkritiek van Herbert Marcuse. Amsterdam : Buijten en Schipperheijn. 
